\title{
Learning through challenge for prospective elementary teachers, experienced and beginning teachers, mathematics teacher educators and researchers, and education systems
}

\author{
Kim Beswick ${ }^{1}$ \\ Published online: 8 May 2018 \\ (C) Springer Science+Business Media B.V., part of Springer Nature 2018
}

It is well established that challenge and learning are connected and that the most profound learning is likely to occur in situations that the learner experiences as challenging and yet are successfully negotiated. This issue includes papers that describe ways in which challenge might lead to important learning for preservice elementary teachers (Lovin et al.), teachers, and mathematicians (Cooper and Karsenty). Norton and Zhang offer a challenge to mathematics educators and policy makers through their analysis of mathematical competence of prospective elementary students in Australia and China. While not focussed on international comparison, Lovin et al. reference curriculum differences between countries such as the USA and Japan in explaining the prevalence of particular ways of thinking among their participants. Finally, Losano et al. provide a powerful analysis of the challenges faced by a beginning secondary mathematics teacher and the implications that these have for preservice teacher education. Juxtaposing issues of policy and questions about what is to be valued in mathematics education (Norton and Zhang) with the experiences of a beginning teacher for, whom the broader policy milieu is as yet beyond the scope of the world in which she is constructing herself as a mathematics teacher (Losanao et al.), presents its own challenge to readers: That of positioning our research and thinking in relation to big picture issues while simultaneously maintaining attention to the human business of teaching and learning and mathematics in classrooms.

Concerns about the mathematical knowledge of prospective elementary teachers are long-standing and well documented. Two of the papers in this issue (Lovin et al. and Cooper and Karsenty) inform our understanding of how initial teacher education programs might help prospective elementary teachers to build the knowledge that they will need to work effectively with school students.

Kim Beswick

kim.beswick@utas.edu.au

1 University of Tasmania, Launceston, Australia 
Fractions are known to cause difficulty for prospective teachers as well as for school students. Improved understanding of the ways in which teachers work with and reason about fractions and how their thinking in relation to fractions develops is important to designing teacher education programs that are likely to facilitate the development of prospective teachers' knowledge. To this end LouAnn Lovin, Alexis Steven, John Siegfried, Jesse Wilkins, and Anderson Norton report evidence based on the responses of 109 prospective elementary teachers to tasks carefully designed to elicit the range of fraction schemes, that prospective elementary teachers follow the same developmental trajectory in relation to fraction knowledge as school students. Lovin et al. recommend that initial teacher education courses include opportunities for prospective teachers to move beyond part-whole thinking that appears to dominate US curricula (and others), to encourage the more iterative thinking that characterises curricula in other countries such as Japan. They believe that incorporating problems that are likely to challenge prospective teachers because they require reasoning with three levels of units, as well as problems that involve working with improper fractions would be beneficial.

Jason Cooper and Ronnie Karsenty report on a novel way in which elementary school teachers and university mathematicians interacted in a mutually challenging and yet beneficial way. Using commognition, in which cognition is defined as communication, as their overarching framework, they consider the professional development session they describe, as the context in which two discourse communities (that of teachers and that of mathematicians) interacted to develop the discourse of mathematics teaching. Through a detailed analysis of three episodes that occurred in a single session on division with remainder that was led by a mathematics professor, they demonstrate how the discourses of the teachers and the mathematician interacted to produce new insights for all concerned. In particular, ambiguities of language and notation fuelled rather than hindered the discussions, providing insights into the meaning of nature of equivalence, the meaning of the remainder and its connection with fractions. Among this learning was a possible student learning trajectory from remainders (with a potential to be divided) to fractions (as the result of division). Cooper and Karsenty point to an important difference between the discourse that occurred in the professional development and that which occurs in school classrooms: In classrooms one would expect that the students' discourse would ultimately match that of the teacher, whereas in this professional development session members of both discourse communities were challenged by and learned from the others' discourse.

Stephen Norton and Qinqiong Zhang present a challenge of a different sort. They report further evidence that Chinese prospective elementary teachers have greater mastery of basic facts and calculation procedures than their Australian counterparts. The authors argue that the differences are reflective of differing views of the nature of mathematics and how it is best taught, with stronger adherence to a hierarchical view of mathematics and teachercentred pedagogies in China than in Australia where they contend, applications of mathematics and student-centred pedagogies predominate. Conversely, they include data that suggest that there is concern among Chinese academics that facility with calculations unaided by technology may not mean that these prospective teachers have deep or connected understandings. Norton and Zhiang acknowledge that their findings might be dismissed on a number of grounds. Nevertheless, they present a challenge to policy makers and teacher educators and in both Eastern and Western traditions to consider what is valued in mathematics education (as well as in education more broadly), what it is that we want students to learn from school mathematics, and, hence, what teachers need to know and how teacher education might be structured to facilitate these outcomes. 
In the context of the very broad political and ideological questions that Norton and Zhang bring to mind, the focus on a single teacher navigating the transition from prospective teacher to beginning teacher that Leticia Losano, Dario Fiorentini and Mónica Villarreal bring is particularly revealing. The protagonist in their report also grappled with the kind of mathematics that she should teach, and that should be taught, as well as how best to teach it. Using narrative analysis and drawing on data collected at several points across the transition period, Losano et al. document the tensions and challenges of a beginning mathematics teacher. These struggles originate in the diversity of voices-from her past experiences as a school student and prospective teacher, colleagues, and groups of students of differing grade levels - that call and constrain her in different ways, the resources available to her in the particular school context, and her own perceived current and desired future identities. Losano et al. take a dynamic view of identity as dialogically constituted in the interactions of the social context and the individual, and in which the individual's identity is improvised in response to challenges. They paint a picture of a novice teacher both fitting in with, adapting to, and challenging practices in her school during a period of her career that we know can be pivotal.

The reports in this issue all contribute to advancing our understanding of the ways in which teachers of mathematics develop and learn in response to challenge, and how our actions as teachers, teacher educators, and researchers can shape the social contexts in which we each work. By reporting on: the similarity of learning for school students and prospective teachers (Lovin et al.); learning in and from unusual contexts, such as a mathematician leading a professional development session for elementary teachers (Cooper and Karsenty); contrasting the capability of Australian and Chinese prospective students in relation to particular types of mathematical tasks (Norton and Zhang); and exploring the identity development of a novice secondary mathematics teacher (Losano et al.) they illustrate that we have much yet to learn about the ways in which teachers learn and the ways in which mathematics teacher educators can influence that learning. 